\title{
Dilemma of Empowerment: Responsibility Attribution in Prison Counseling
}

\author{
Guo Jing-ying \\ Correspondence: Department of English, Zhejiang Police Vocational Academy, Hangzhou City, Zhejiang Province, \\ China.
}

Received: January 9, 2014 Accepted: January 24, 2014 Available online: February 12, 2014

doi:10.11114/smc.v2i1.347

URL: http://dx.doi.org/10.11114/smc.v2i1.347

\begin{abstract}
Prison counseling as a new intervening tool to reform inmates in China has provided a site in which inmates could have more rights to confidentiality or equality and be motivated towards positive change. In actual practice, however, there are occasions in which the police counselors do not seem to act as facilitators and helpers as they are supposed to. This paper, drawing on discursive psychology, looks into how the police counselors attribute responsibility for the problems that drive the inmate clients to the counseling by focusing on variant cases. Analysis reveals that two main discursive devices, tag questions and reformulation, are employed by the police counselors in an attempt to deflect responsibility for the problems of the inmate clients and the solution to these problems from the prison and stakeholders within the prison. Prison counseling is caught in a dilemma of empowerment.
\end{abstract}

Keywords: discursive psychology, empowerment, responsibility attribution, discursive device

\section{Introduction}

The question asked in criminal justice system has long been changed from asking "whether prison works" to "what works". Cultural education, vocational education and other rehabilitation programs are all designed to empower inmates so that they could be more successful in their future reintegration into the society upon release. The application of psychology to people convicted of offences began around the late 20th century. Mental health services are considered to make a difference to inmates' lives and help them feel more confident about their future. A lot of researches have identified, developed and improved counseling programs conducted in correctional institutions (e.g., Masters, 2004; Sun, 2008; Zhang, 2007; Wu, 2010). Quantitative approaches have been employed to prove the causal relationship between counseling sessions and the reduction of recidivism rates (e.g., Whiteley \& Hosford, 1983; Durcan, 2008; Correia, 2009; Ma et al., 2007). China has about 1.5 to 1.6 million inmates held in about 700 prisons. In order to reform and educate inmates in a more effective and scientific way, knowledge and skills from other fields and countries have been introduced into the prison system. In 1981, the Eighth National Work Conference on Reform-through-labor in China stipulated that scientific knowledge such as psychology should be applied in reforming criminals. Since then, counseling services have been booming in more than 93\% of China's prisons. As of June, 2010, the number of prison officials who have obtained certifications of counseling has reached 15,329 (Yang, 2010), and in 2004, about 208,743 inmates voluntarily requested counseling services ( $\mathrm{Wu}, 2010)$. After more than 30 years' practice in China, prison counseling has played an important role in helping inmates with their rehabilitation, maintaining the order and security of the prison and reducing recidivism. However, the rapid development of prison counseling has been imbued with controversies. Recently, there have been heated debates about whether providing counseling services in a context in which security is priority is ethical, for the context might mitigate against therapeutic change (e.g., McGuire, 1997; Correia, 2009; Yang, 2010; Feng, 2011). In addition, prison is a site in which people handle people. Considering that counseling services in China's prisons are mostly conducted by police officials who have acquired counseling certificates, how counselors in police uniform could put aside their roles as police officials and treat those entering the counseling rooms as clients equal to them is in question (Chen \& Nie, 2008; Guo, 2011; Shao, 2012).

"Dialogue is the heart of the helping process, enabling clients and helpers to engage collaboratively and productively in the helping process" (Egan, 2010: 91). During the process of the talk, both parties try to understand, interpret and respond to each other's utterances in order to accomplish their mutual and respective goals, one of which is to attribute responsibilities. Kurria and Wahlstro"m (2005) look in detail into moral reasoning in action as it unfolds in one couple therapy session and conclude that responsibility placing is an act of executing moral judgment. Tilbury and 
Colic-Peisker (2006) explore how employers use a number of discursive devices, which are termed as "exoneration utterances", to attribute inequitable employment outcomes to the market. Thus, the responsibility for their possible discrimination against migrants and refugees could be deflected. Abell \& Stokoe (1999) examine how Princess Diana and Martin Bashir in the BBC interview attribute blame by employing discursive strategies such as script formulation, stake management, footing shifts and progressive narrative. The ways by which participants in conversation attribute responsibility could reveal the relationship between or among participants and their understanding of the conversation. Changing inmates to take responsibility for themselves and their future is the starting point from which correction and rehabilitation of inmates begins. A core message of prison counseling is that inmate clients could take the responsibility for change of behavior or attitude. Prior studies have seldom considered how responsibility for change is attributed in prison counseling. Inmate clients have been taken for granted to be beneficiaries. Through detailed analysis of responsibility attribution in situ from the perspective of discourse analysis, this paper hopes to shed light on the relationship between the counselors and inmates who are both in uniform and how prison counseling which has drawn criticism and suspicions is conducted in China's prisons.

\section{Method}

Discourse analysis not only pays attention to linguistic forms and contents but the context in which the interaction takes place. The method used in this paper is discursive psychology (hereafter DP) (Edwards \& Potter, 1992; Potter, 1996) which is informed by discourse analysis (Potter \& Wetherell, 1987), ethnomethodology (Heritage, 1984), conversation analysis (Sacks, 1992), and Billig's (1996) rhetorical strategies esp. his concepts of persuasion and particularization. Language in DP is first and foremost considered as action-oriented. People resort to discursive devices such as extreme-case formulation, manipulation of details, shifts in footing, the construction of consensus and collaboration (Abell \& Stokoe, 1999, p. 298), etc. The purpose is to make their descriptions and accounts real and authentic and the most important of all to accomplish certain functions. Since counseling theories and technologies are applied in prison counseling, the mental states or inner mind seem to be the focus of both research and practice of prison counseling. However, DP regards that that there is no essence lying out. Therefore, rather than regarding what people say reflects their underlying mental state, how psychological entities such as attitudes, identities and memory are constructed by participants in their interaction is the focus of DP.

In recent development of DP, there has been an increasing interest in studying how issues such as responsibility placing, blame assigning or understanding are managed in institutions. In this way, how particular institutions and organizations are done could be revealed. DP researches into institutions include studies of child protection helpline interaction (Potter \& Hepburn, 2003; Hepburn 2004), police interrogations (Edwards, 2006), court judgment (MacMartin, 2003), and therapeutic and medical sessions (Peräkylä, 1995). The research question asked is not what the speaker is thinking about or whether he is telling the truth, but how the talk is done. The inconsistencies and variability in the talk are regarded as meaningful and worthwhile to be examined. In this paper, how the police counselors construct prison counseling through responsibility attribution is studied. Variant cases are analytic concerns of this paper with the purpose of reflecting on how the police counselors understand their identities, counseling, crime and punishment. Discursive devices used by the police counselors are considered as discourse evidence of whether they empower or control inmate clients.

The data in this paper comes from my $\mathrm{PhD}$ research into prison counseling consisting of 10 counseling sessions conducted between prison counselors and inmate clients. The data were collected from two main sources: participant observation and obtaining recordings provided by two prisons in southern China. Any information might disclose the identities of both parties in prison counseling were either changed or deleted. The transcription convention employed is not strictly Jeffersonian system (Atkinson \& Heritage, 1984: ix-xvi). All of these data is originally Mandarin Chinese. The first version of data is in Chinese pinyin and the literal meaning of the original Chinese is provided in the second version. All the participants are pseudonymed with the police counselors as PC and the inmate clients as Wang, Li, Qian, etc. This paper does not seek to make generalizations about what is going on in prison counseling in China's prisons or to claim universalities of the results. Rather the aim is to provide a window through which we could learn how prisons in China are done.

\section{Analysis and Discussion}

In accordance with prison rules and regulations, inmates in China have the right to apply for counseling services voluntarily and decide whether follow-up services are needed. At the beginning of each counseling session, the police counselors generally declare to the inmate clients their right to equality and confidentiality. During the process of counseling, the police counselors encourage, respond to and provide answers to the inmate clients. Welcome to have follow-up counseling sessions is always extended to the inmate clients. It seems that inmates are granted rights that they have never enjoyed or couldn't enjoy in other circumstances within the prison. However, after detailed analysis of how 
the police counselors attribute responsibilities during and after problems that drive the inmate clients to the counseling are presented, some police counselors are found to be caught in a dilemma of empowering and disempowering as evidenced by two main discursive devices employed by them: tag questions and reformulation.

\subsection{Tag Questions}

Tag questions serve to seek confirmation of the statement that occurs before the tag ( $\mathrm{Li}$ and Thompson, 1981). In these 10 counseling sessions, there are in all 386 occasions in which the police counselors raise tag questions in the form of either "right" (duiba, duibudui, shibushi, shiba) or "ok" (haobuhao, haoba) after a declarative sentence offering advice or comments or an open question. These tag questions usually require the respondent to provide an answer in the form of yes/no. In the majority of occasions, the inmate clients provide the yes response without hesitation. However, since the counseling is conduced in the context of prisons and by the counselors in police uniform, the provision of agreement is suspected of fulfilling phatic function if the inmate clients do not want to threaten the face of the police counselors. In some variant cases, some inmate clients are found to have expressed their disagreement in an elaborate way.

Extract 1 (Chinese pinyin)

01PC: wo. wo yaoshi dui lingdao bu shufu wo bu keneng dangzhe lingdao,

02 zai ta bangongshi limian qu gen lingdao fa yidun piqi,

03 mingtian wo jiu buyong zai zheli hun, hunfan chi le.

04 jiushishuo qingxu de faxie hai yao jiangjiu yiding de jiqiao.

05Wang: zhe shi de=

06PC: =zai mouzhong butong de huanjing xia, yao you yizhong fuhe huanjing de shouduan,

07 ni shuo ne(.) ni shuo ne, duiba?

08PC: jiushishuo...(utterances omitted)

Extract 1 (English version)

01PC: I. If I do not like my superior, it is impossible for me

02 to lose my temper in his office.

03 Otherwise, I might be fired tomorrow.

04 What I mean is that we also need to pay attention to the method when venting emotions.

05Wang: This is correct=

06PC: =Methods should be suitable to certain different circumstances.

07

What do you think (.) What do you think, right?

08PC: That is to say...(utterances omitted)

In this case, the inmate client's narration centers on his experience of having lost his temper in front of custodial officials and been punished for it. He has reiterated during counseling that he should have the right to let out his emotions. In this extract, the police counselor takes himself as an example (lines 1-4), implicating to the inmate client that he should not lose his temper in front of the person who is in charge (1), should be careful with his choice of the place (line 2) and consider possible consequences (line 3). In a roundabout way, the police counselor is making a negative evaluation of the inmate client who does not have a clear idea of who and where he is. In line 4 , the police counselor concludes that the inmate client should pay attention to the method, which is recognized by the inmate client in line 5. It is worth noting that instead of providing a complete agreement by uttering a simple response "yes" or "correct", the inmate client prefaces his agreement with the definitive "this" (zhe). The definitive serves to limit his agreement on the police counselors' utterances from line 1 through line 4 , implicating that what the police counselor has said per se is correct but does not hold true for his situation. In line 6, the police counselor continues previous topic by declaring that a good method should be suitable to the environment. The underlying meaning is that the inmate client's way of letting out his emotions is wrong. Acting thus, the responsibility for the inmate client's problem of being punished is deflected from the custodial officials to the inmate client who acted wrongly in a wrong place.

Following that, the police counselor asks about the opinion of the inmate client by raising an open question "what do you think" (ni shuo ne, line 7). However, after a brief pause, the repetitive open question is changed to a closed one 
when the tag question "right" (duiba) is added at the end of his utterances. The invitation that the inmate client could express his opinion on his advice put forward in line 6 is then limited to a yes/no confirmation-seeking elicitation. The 3 -second silence afterwards signals the police counselor's intention to hand over the speaking floor. In line 8, seeing that the inmate client does not provide an affirmative answer to his tag question, the police counselor has to re-claim the speaking floor. The inmate client's limited agreement in line 5 and his reluctance to claim the floor after line 7 signal his implicit resistance and his unwillingness to express his disagreement.

Extract 2 (Chinese version)

09PC: ...ni, ni zaoshang qilai, nimen an zheli guiding, zuoxi shijian.

10 kending you guilv de ma. ni yijing liangge duo yue le,

11 haiyou shenme hao jinzhang de, duibudui a?

12 meitian zaoshang qilai ni yinggai gan shenme, ni yao xiang hao.

13 zhe yitian yinggai gan shenme.

14 erqie zhe yitian zaoshang qilai jiu yinggai xiang,

15 wo jintian yiding yao nuli gongzuo, shibushi?

16Li: nali laideji xiang a, hehe.

Extract 2 (English version)

09PC: ... You get up in the morning in accordance with the schedule here.

10 There is surely a routine. You have been here for more than two months.

11 There is nothing to be nervous about, right or not?

12 You should plan what you should do when you get up in the morning

13 and what you should do for the whole day.

14 Besides, you should think as soon as you get up

15 that I must work hard today, right or not?

16Li: There is no time for me to think at all. Hehe.

It is commonly agreed that new inmates are more likely to feel disappointed, anxious and sad. Therefore, they are generally placed in the orientation unit before they are assigned. In this case, the inmate client is new in this prison and has asked for counseling services for prison adjustment issues. From line 9 through 15, the police counselor seems to describe the life in the prison. However, the modifiers "surely" (kending) and "more than" (duo) used by the police counselor in line 10 have two implications. First, the inmate client should accept the fact that the life in the prison is different from that outside. Since the inmate client has come to the prison due to his criminal behavior, the responsibility for prison adjustment issue lies in the inmate client instead of the police counselor or the prison. Second, the inmate client should have adapted to prison life within a less period of time because he has come here for more than two months. The conclusion in line 11 seems to function as a comfort that the inmate client needn't worry but might serve as an expression of dissatisfaction with the inmate client's inability to adapt to prison life. The modal auxiliary verb "should" (yinggai) is always used to offer advice or opinions. In lines 12, 13 and 14, what the inmate client is advised to do by the police counselor is all provided using the modal verb "should", constructing the advice not only preferable but obligatory.

The police counselor's tag questions "right or not" after his advice in lines 11 and 15 (duibudui and shibushi) put the inmate client in a position to provide an either positive or negative response, indicating his intention to elicit an explicit confirmation. However, there is no apparent pause or silence after the first tag question (line 11), making the confirmation seeking rather perfunctory. The inmate client claims the speaking floor in line 16 and his response that "there is no time for me to think at all" (nali laideji xiang $a$, line 16) serves to refute the police counselor's advice in an indirect way. The underlying meaning is that it is not his lack of ability but the tight schedule in the prison leads to his problem. Acting thus, the responsibility for his problem is then attributed to external factors other than himself. In an implicit way, the inmate client expresses his dissatisfaction with the police counselor's advice to his problem.

(Chinese pinyin)

17PC: ...(utterances omitted) na ni ye xiang zuo hao yidian jiu dui le o $\uparrow$ duibudui a? ni zai zheli. ni shuo gang lai de shihou henduo dongxi ni bu xiguan:: 
19 renjia jiao ni zheyang jiao ni nayang, ni dou mei zuohao.

20 o. zuohao yao danxin ai piping,

21 zhe doushi::en, keyi lijie de, duibudui a? wo ye lijie. danshi,

22 ni yao jinkuai de ziji shiying huanjing, shiying zheli de shenghuo o, shibushi?

23 haohao gaizao, ni a::zhenshi,

24 ni kan ni xiang yong yao chisi name duo gongren.

25 ni zuofan, ni liyong zuofan zhege bianli ba du fang jinqu,

26 na ni shuo ni zhege::tai edu le, duibudui?

27 zhege zuofa shi zhende feichang edu de...(utterances omitted)

(English version)

17PC: ... Then you also want to do better, right or not?

18 You are here. You said that when you just came here you were not used to many things::

19 You did not do well things that you were asked to do.

20 Oh. You were worried that you would be criticized for not doing well.

21 These are understandable, right or not? I could understand, but

22 you should adapt to the environment and the life here as soon as possible, right or not?

23 Reform well. You are:: really.

24 You wanted to poison so many workers to death.

25 You are a cooker and you make use of it to put poison in the food.

26 Your... is so malicious, right or not?

27 Your behavior is really very malicious...(utterances omitted)

After several exchange of utterances, the police counselor begins to make a summery which consists of two parts: empathy expressing (lines 17-21) and evaluation making (lines 22-28). In the first part, the police counselor states his understanding of the inmate client's prison adjustment issue. The conjunction "but" (danshi, line 16) signals his readiness to make a comment contrary to the first part. In line 22 , the advice put forward by the police counselor is carefully designed by using the modal verb "should" (yinggai) which obligates the prison adjustment issue to the inmate

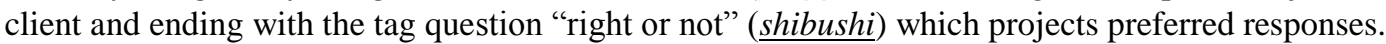

The adjective in the sentence "you are::really" (ni a::zhenshi) in line 23 is absent. From line 24, the police counselor turns to talking about the inmate client's poisoning behavior. We could assume that the police counselor might on the one hand wants to show his disapproval of the inmate client's criminal act, and on the other relate the inmate client's prison adjustment issue to his previous criminal behavior. The subject of his utterance in line 26 is ambiguous, but the police counselor defines it as malicious. In line 27, the subject is soon filled in and the police counselor limits his evaluation to the inmate client's behavior. However, the evaluation is upgraded by adding the two adverbs "really" and "very", which implicates his strong disagreement. Throughout this extract, the focus of the talk is not on whether the inmate client has been unfairly asked to do things by either custodial officials or fellow inmates. Nor does the inmate client have the opportunity to raise a different opinion, for there is no apparent pause or silence after the four tag questions (lines 17, 21, 22, 26). The topic has been shifted from the inmate client's prison adaptation issue to his criminal act. The underlying meaning is that the inmate client is having only himself to blame and the connection between his problem and criminal act is made. The responsibility for the inmate client's problem and the solution to this problem is then placed solely on the inmate client.

\subsection{Reformulation}

Reformulation is a way that the speaker reinterprets his own or other speaker's previous fragment of discourse for clarification or confirmation. During prison counseling, when problems that drive inmate clients to the counseling involve custodial officials or the prison, the police counselors generally try to elicit more detailed information and discuss with the inmate clients about how to address these problems. However, some police counselors will reformulate these problems as either general or particular ones. The responsibility is then deflected from custodial officials with whom the police counselors work and the prison that the police counselors represent.

Extract 3 (Chinese pinyin) 
28PC: ni. ni. ni jue bu juede, jianyu limian ye suanshi yige xiao shehui a?

29 youmeiyou zhezhong ganjue?

30Qian: benlai jiushi yige quanzi ma. quanzi jiushi yige xiao shehui.

31PC: dui a. jianyu jiushi yige xiao shehui=

32Qian: =dui=

33PC: =qishi ni ye shi zai shehui shang dai guo de, duiba?

34 qishi shehui shang zhezhong bu gongping de xianxiang ye henduo.

Extract 3 (English version)

28PC: You. You. Don't you think that the prison is like a small society?

29 Do you have such a feeling?

30Qian: It is actually a circle. This circle is a small society.

31PC: Correct. Prison is a small society=

32Qian: $=$ Right $=$

33PC: =You have previously stayed in the society, right?

34 In fact there are also many unfair things in the society.

The inmate client in this case regards custodial officials unfair to him. In this extract, the police counselor invites the inmate client to compare the prison to the society by putting forward two rhetorical questions in lines 28 and 29 . Acting thus, the inmate client is oriented to accepting such a comparison since he is unlikely to raise a different opinion from the police counselor. After getting a satisfied answer, the police counselor changes the comparison between the prison and the society in line 28 to the factual statement that the prison is a society in line 31 . In line 33 , the police counselor pursues the topic after eliciting the inmate client's agreement by concluding that since the inmate client has stayed in the society before being put behind bars he must have experienced unfairness. The purpose of such a reference to the society is to persuade the inmate client that he should not idealize the prison and accept the existence of unfairness in the prison. Thus the existence of the inmate client's problem is justified.

What is absent in the police counselor's discourse is the elicitation of details of the unfair treatment of the inmate client and the provision of information about what measures that the inmate client could take to protect his legal rights. The focus of their talk is not on what custodial officials have done or what the inmate client could do to change his present situation, but on what the inmate client could do with himself. The problem of the prison is extended to an issue existing in the whole society and the nature of the problems is reformulated to be social one. Therefore, it is the inmate client who should change his conception of the prison. The responsibility for the inmate client's problem is then deflected from both custodial officials and the prison.

Extract 4 (Chinese pinyin)

35PC: yinwei::buguang shi nimen::zai limian (.) you zhezhong qingkuang,

36 qishi ren zai waimian o, you (.) you xuduo qingkuang.

37 women shuo:wo mubiao ding xialai le o::

38 keshi zai:shixian mubiao de guocheng zhong o::

39 zong hui chuxian (.) chuxian gezhonggeyang de shiqing,

40 erqie:keneng mubiao hui (.) hui buneng shixian huozhe::yanchi shixian o:

41 zhexie dongxi doushi yinggai::ni yinggai zhidao de, ni shuo duibudui?

42Xu: hehe. zhe shi dui de.

Extract 4 (English version)

35PC: Because not only you have situations like this inside,

36 people outside actually also have similar situations.

37 What we mean is that I have set our goals,

38 but during the process of achieving our goals,

39 there are always different situations arising. 
40 In addition, our goals might not be achieved or held up.

41 You should know this. Do you think it is correct?

42Xu: Hehe. This is correct.

The inmate client in this case has applied for prison transfer hoping to serve his sentence in a different prison and has provided the police counselor his reasons for such a transfer and his concerns and anxiety over the result. The inmate client might attend this counseling session in anticipation of having inside information such as the result of his application. In this extract, the police counselor also invites the inmate client to make a comparison between the inside (the prison, line 35) and the outside (the world beyond the prison, line 36). The knowledge that doing things has two different results: bad or good, is packaged as a common one that everybody should be aware of (lines 37-40). The inmate client's problem of whether he could have prison transfer is then reformulated to be a problem of whether the inmate client has the common sense that doing things will not necessarily have good result. Therefore, if the result turns out contrary to his expectations, the responsibility should not be attributed to the prison. In this extract, the police counselor avoids talking about how the inmate client could do to have more chances of achieving his goal but focuses on preparing the inmate client for possible failure. The rhetorical question beginning with the preface "do you think" ( $n i$ shuo, line 41) also orients the inmate client to providing the yes answer. The response of the inmate client in line 42 is like the one in extract 1 consisting of the preface "this" (zhe) and the affirmative answer "correct" (duide). Such a limited agreement might signal his implicit dissatisfaction.

Extract 6 (Chinese pinyin)

43Zhao: ...(utterances omitted) ta gen wo jiang:

44 "ni xiangxin zhege dongxi ganhuo jiu zhende nenggou gan chulai ma?

45 shibushi? xianzai de shehui jiushi zheyang."

46 ni shuo ni rang wo zenme lijie?

47PC: e. ni shi juede nimen fen-jianqu minjing,

48 gen ni tanhua de fangshi rang ni ganjue bijiao nanyi jieshou, shiba?

Extract 6 (English version)

43Zhao:...(utterances omitted) He told me:

44 "Do you really believe that this could be obtained by working?

45 Right or not? This is our society."

46 Could you tell me how I understand this?

47PC: Uh. You think that it is the custodial official in your sub-jianqu's

48 way of talking with you that makes you hard to accept, right?

In this case, the inmate client has provided details about how his points were reduced and considered it unfair. In the majority of China's prisons, the performance of inmates is evaluated by 100-point check-up system. The points are closely related to inmates' privileges such as reduction of sentence or parole. The inmate client has reiterated that what he asked for was fairness. The comment of concerned custodial official on fairness which is referred to as the definitive "this" (zhege, line 44) is quoted in lines 44-45. The direct quotation of the official "in the guise of ostensibly verbatim recall" (Edwards \& Potter, 1992:161) is made not only to make his presentation factual but to demonstrate the custodial official's suspicions about the existence of fairness. Acting thus, the negative image of the custodial official who is supposed to stand for and uphold fairness but does not believe in it is constructed. There is a 3-second silence afterwards indicating his intention to wait for the police counselor's comments. Seeing that the police counselor gives up the speaking floor, the inmate client pursues this topic by putting forward a rhetorical question that "could you tell me how I understand this" (ni shuo ni rang wo zenme lijie, line 46), which indicates not only his insistence on this topic but his effort to seek agreement from the police counselor. The silence as long as 7 second afterwards implies the police counselor's reluctance to claim the speaking floor. On the one hand, the police counselor might risk the interests of the custodial official who is also one of his colleagues if he agrees with the inmate client. On the other, he might be 
evaluated to be not neutral if he speaks for the custodial official.

In line 47, the police counselor has to break the silence. However, rather than making comment on the quotation or responding to the question raised by the inmate client in line 46, the police counselor says "you think that it is the custodial official in your sub-jianqu's way of talking with you that makes you hard to accept, right" (ni shi juede nimen fen-jianqu minjing, gen ni tanhua de fangshi rang ni ganjue bijiao nanyi jieshou, shiba). Acting thus, the police counselor implicitly reformulates the problem from one involving the custodial official's possible unfair treatment to the one involving the official's ways of communication. This reformulation begins with the preface "you think" (ni shi juede), constucting the reformulation as asking for clarification of the inmate client's original meaning. The tag question "right" (shiba) at the end of the sentence is resorted to so that he does not seem to impose his reformulation on the innate client. The underlying meaning of the reformulation is that the custodial official still acts in line with his role as a qualified officer but might not be good at skills of communication. Responsibility of the custodial official for the inmate client's problem is then mitigated.

\section{Conclusion}

Empowerment has been an oft-quoted concept in health care professions and is defined as "a process of increasing personal, interpersonal, or political power so that individuals can take action to improve their life situations" (Gutiérrez, 1990:149). Prison counseling has provided a new communication line empowering inmates to share, speak up and discuss with police counselors so that their abilities to understand and solve problems could be improved. Constrained by counseling theories or technologies, the counselors in police uniform all avoid giving orders or imposing on the inmate clients what they are expected to do in a direct way. However, after detailed analysis of naturally occurring counseling sessions, three main problems are found to be a hindrance of realizing such a goal. First, expecting the inmate clients to be both autonomous and compliant might result in conflicts. On the one hand, inmate clients should take the initiatives in taking actions to solve their problems, but on the other the confined institution and rigid prison rules and regulations require them to be compliant so that the order and peace of the prison could be maintained. In addition, the asymmetry between inmates and prison officials lead to inmates' total dependency on the prison and prison officials for both basic necessities and privileges. Therefore, the inmate clients in these cases resort to limited agreement or giving up the speaking floor instead of expressing explicit disagreement. Their aim is to please the police counselors and avoid possible consequences. Second, empowering inmate clients imply that they should be put at the center rather than on the periphery of the counseling. The police counselors offer their advice ending with the tag questions to provide the inmate clients the right to refute or provide a different opinion. However, in the context of prisons, these tag questions serve to orient the inmate clients to providing a preferred response, for it is unusual for inmates, out of fear of being evaluated as uncooperative or defiant, to disagree with the police officials. Furthermore, tag questions without pause or silence afterwards indicates that either the response of the inmate clients is of no interest to the police counselors or their function of seeking confirmation is no more than perfunctory. Reformulation is usually used to achieve mutual understanding. The communicative functions of reformulation in these cases is found to be a strategy to change the nature of the problems so that the responsibility for the inmate client's problems and the solution to these problems is either mitigated or deflected from the prison and the stakeholders within the prison. The knowledge that the inmate clients could resort to when they have complaints against custodial officials or prison administration is absent in the discourse of the police counselors. The interests of the prison have taken priority. Third, the perception of clients can significantly affect the way by which police counselors interact with their clients. Some police counselors, by relating the inmate clients' problems to their criminal history, have regarded the inmate clients as criminals rather than clients.

The police counselors in China all have obtained counseling certificates. However, detailed discourse analysis of variant cases of counseling in situ reveals that what has learned might not necessarily be applied in actual practice. Counselors are supposed to be neutral, but the dual identities of the police counselors make them caught in a dilemma of empowering the inmate clients and managing the interests of themselves, custodial officials and prison administration at the same time. Despite the usual 45-minute time constraints of each counseling session, the discourse of both the inmate clients and police counselors is characterized by being veiled and roundabout. The efforts made by the inmate clients to hold back their disagreement and by the police counselors to implicitly control the counseling through tag questions and reformulation affect counseling effectiveness. There have been rules and regulations emphasizing basic principles of counseling and outlining how police counselors report problems involving custodial officials and prison administration. There are also procedures for coordinating related departments for the solution to these problems. Given that security is the priority of the prison and the majority of prison counseling services in China will continue to be conducted by the police counselors due to concerns about the cost and security, it is unlikely that police counselors could conduct prison counseling without taking the interests of the prison and stakeholders within the prison into account and that the hierarchical relationship between the police counselors and inmate clients could be changed. However, it is feasible to devise practice guidelines that regulate specifically how police counselors respond to and interact with inmate clients in 
a more direct and candid way during prison counseling. Otherwise, the police counselors who could not put their identities as police officials aside will continue to act as the protectors of the interests of the prisons, which will not facilitate the trust in the counseling relationship. As a result, prison counseling might end up becoming another alternative to persuading or even worse to coercing inmate clients into being compliant. It is only when the police counselors could be protected from possible consequences for not speaking for custodial officials and the prison and prevented from acting as police officials will they speak in the inmate clients' shoes. Then the inmate clients will begin to be empowered to change their life situations and take responsibilities for their actions.

\section{Notes:}

1. jian-qu: the prison in China is usually divided into different jian-qu (similar to unit or wing in America) for better management and in some prisons jian-qu might be sub-divided into sub-jian-qu.

2. This paper is partial result of the research project "Dilemma of Empowerment: Responsibility Attribution in Prison Counseling" funded by Institute of Crime Prevention, Department of Justice, China (2013).

\section{Appendix: Transcription Symbols}

(.) A dot in parentheses indicates a pause of no more than one-tenth of a second.

(0.3) The number in brackets indicates a pause in seconds.

:: Colons indicate the preceding sound is prolonged.

$=\quad$ The equal sign indicates no gap between the two lines.

$\uparrow \quad$ Upward arrow indicates rising intonation.

\section{References}

Abell, J., \& Stokoe, E. H. (1999). 'I Take Full Responsibility, I Take Some Responsibility, I'll Take Half of It But No More Than That': Princess Diana and the negotiation of blame in the 'Panorama' interview. Discourse Studies, 1(3), 297-319.

Atkinson, J. M., \& Heritage, J. (Eds.). (1984). Structures of Social Action: Studies in Conversation Analysis. Cambridge, UK: Cambridge University Press.

Billig, M. (1996). Arguing and Thinking: A Rhetorical Approach to Social Psychology. Cambridge: Cambridge University Press.

Chen, L. Z., \& Nie, W. W. (2008). The integration of offender psychological correction and "three major correctional methods". China Prison Journal, 1, 120-122.

Correia, K. M. (2009). A handbook for Correctional Psychologists: Guidance for the Prison Practitioner (2nd.). Springfield, Illinois: Charles C. Thomas Publisher Ltd.

Durcan, G. (2008). From the Inside: Experiences of Prison Mental Health Care. London: Sainsbury Centre for Mental Health.

Edwards, D. (2006). Facts, norms and dispositions: Practical uses of the modal verb would in police interrogations. Discourse Studies, 8(4), 475-501.

Edwards, D., \& Potter, J. (1992). Discursive Psychology. London: Sage.

Egan, G. (2010). The Skilled Helper: A Problem-management and Opportunity-development Approach to Helping. Pacific Grove, CA: Brooks/Cole.

Feng, Y. P. (2011). The analysis and strategy of resistance in offender counseling. Science of Social Psychology, 2, 27-31.

Guo, J. Y. (2011). Gentle order and weak compliance: Conversation analysis of advice and delivery and response in criminal psychological counseling. Journal of Guangdong University of Foreign Studies, 5, 64-69.

Gutiérrez, L. M. (1990). Working with Women of Color: An Empowerment Perspective. Social Work, 35(2), $149-154$.

Hepburn, A. (2004). Crying: Notes on description, transcription and interaction. Research on Language and Social Interaction, 37, 251-90.

Heritage, J. (1984). Garfinkel and Ethnomethodology. Cambridge: Polity Press.

Kurri, K., \& Wahlstro“m, J. (2005). Placement of responsibility and moral reasoning in couple therapy. Journal of Family Therapy, 27, 352-369.

Li, C. N., \& Thompson, S. A. (1981). Mandarin Chinese-A Functional Reference Grammar. Berkeley: University of 
California Press.

Ma, L. J., Yang, G. Q., Pan, H. C., \& Zhang, M. (2007). Exploration of applying group therapy to psychological correction of juvenile delinquent offenders. Crime Issues of Juvenile Delinquent Offences, 4, 49-53.

MacMartin, C. (2003). (Un)reasonable doubt? The invocation of children's consent in sexual abuse trail judgments. Discourse \& Society, 13(1), 9-40.

Masters, R. E. (2004). Counseling Criminal Justice Offenders. London, England: Sage.

McGuire, J. (1997). Ethical dilemmas in forensic clinical psychology, Legal and Criminological Psychology, 2 , 177-192.

Peräkylä, A. (1995). AIDS counselling: Institutional Interaction and Clinical Practice. Cambridge: Cambridge University Press.

Potter, J. (1996). Representing Reality: Discourse, Rhetoric and Social Construction. Thousand Oaks, CA: Sage Publications.

Potter, J., \& Hepburn, A. (2003). "I'm a Bit Concerned" - Call openings on a child protection helpline. Research on Language and Social Interaction, 36, 197-240.

Potter, J., \& Wetherell, M. (1987). Discourse and Social Psychology: Beyond Attitudes and Behaviour. London: Sage.

Sacks, H. (1992). Lectures on Conversation, Volumes I and II. Edited by G. Jefferson with Introduction by E.A. Schegloff, Blackwell, Oxford.

Shao, X. S. (2012). Inmate Psychological Correction: Theory and Practice. Beijing: Qunzong Publishing House.

Sun, K. (2008). Correctional Counseling: a Cognitive Growth Perspective. Massachusetts: Jones \& Bartlett Publishers, Inc.

Tilbury, F., \& Colic-Peisker, V. (2006). Deflecting responsibility in employer talk about race discrimination. Discourse \& Society, 17(5), 651-676.

Wu, Z. X. (2010) Techniques of Psychological Treatment towards Prisoners in China. Beijing: Beijing Normal University Publishing Group.

Whiteley, S. M., \& Hosford, R. E. (1983). Counseling in prisons, The Counseling Psychologist, 11(2), 27-34.

Yang, M. G. (2010). Practices and thoughts on criminal psychological correction, presented on Sino-Finnish seminar on corrections and rehabilitation of offenders.

Zhang, E. Y. (2007). Criminal Psychological Correction. Beijing: China Democracy and Legal System publishing House.

\section{(c) $\mathrm{EY}$}

This work is licensed under a Creative Commons Attribution 3.0 License. 